\title{
Human recombinant anti-thyroperoxidase autoantibodies: in vitro cytotoxic activity on papillary thyroid cancer expressing TPO
}

\author{
SA Rebuffat', M Morin ${ }^{1,3}$, B Nguyen', F Castex', B Robert ${ }^{2}$ and S Péraldi-Roux*,1 \\ 'CNRS-UMR 5232, CPID, Faculté de Pharmacie, 15 avenue Charles Flahault, BP I449I, 34093 Montpellier Cedex 5, France; ${ }^{2}$ INSERM-U896, \\ IRCM Val d'Aurelle, UMI, 34298 Montpellier, France
}

BACKGROUND: Thyroid cancers are difficult to treat due to their limited responsiveness to chemo- and radiotherapy. There is thus a great interest in and a need for alternative therapeutic approaches.

RESULTS: We studied the cytotoxic activity of anti-thyroperoxidase autoantibodies (anti-TPO aAbs, expressed in baculovirus/insect cell (B4) and $\mathrm{CHO}$ cells (B4') or purified from patients' sera) against a papillary thyroid cancer (NPA) cell line. Anti-TPO aAbs from patients' sera led to a partial destruction of NPA cell line by complement-dependent cytotoxicity (CDC) and antibody-dependent cell-mediated cytotoxicity (ADCC) and exhibited an anti-proliferative activity. Comparison of the cytotoxic activity of anti-TPO aAbs shows that B4' induced an anti-proliferative effect and a better ADCC than B4, but a lower one than anti-TPO aAbs from patients' sera. Antibody-dependent cell-mediated cytotoxicity was increased when human peripheral blood mononuclear cells were used as effector cells, suggesting that FcyRs, CD64, CD32 and CDI6 are involved. Indeed, anti-TPO aAbs from patients' sera, but not B4 and B4', exhibited CDC activity.

CONCLUSIONS: These data indicate that anti-TPO aAbs display moderate ADCC and anti-proliferative activities on NPA cells; IgG glycosylation appears to be important for cytotoxic activity and ADCC efficiency depends on Fc $\gamma$ R-bearing cells. Finally, recombinant human anti-TPO aAbs cannot yet be considered as an optimal tool for the development of a novel therapeutic approach for thyroid cancer.

British Journal of Cancer (2010) 1 02, 852-86I. doi:I0.1038/sj.bjc.6605464 www.bjcancer.com Published online 9 February 2010

(C) 2010 Cancer Research UK

Keywords: thyroid cancer; anti-TPO antibodies; cytotoxicity; immunotherapy

Thyroid carcinoma accounts for roughly $1 \%$ of all new malignant tumours, and a majority of thyroid cancers are well differentiated, including papillary, follicular and Hürthle cell carcinoma. In most patients, the management of well-differentiated thyroid cancer is partial or complete thyroidectomy in conjunction with chemo- or radioiodine therapy. However, a substantial number of patients with differentiated thyroid cancer do not respond to radioiodine therapy, and $5-20 \%$ of them develop lung metastases, which, in most cases, do not respond to radioiodine therapy and are inoperable. Therefore, new complementary therapeutic approaches could be of interest in the treatment of thyroid carcinomas.

Thyroperoxidase (TPO) is expressed on the apical membrane of both normal and malignant thyroid cells. Indeed, unlike other thyroid-specific antigens, such as thyroglobulin and TSH receptor that are no longer expressed in thyroid carcinomas, TPO expression persists even on poorly differentiated thyroid tumours (Czarnocka et al, 1985). Therefore, TPO expressed at the surface of thyroid cancer cells can be recognised by anti-TPO autoantibodies

*Correspondence: Dr S Péraldi-Roux;

E-mail: sylvie.roux@univ-montpl.fr

${ }^{3}$ Current address: CNRS-UMR 5203, Institut de la Santé et de la Recherche Médicale U661, 34094 Montpellier, France.

Received 23 October 2009; revised 3 November 2009; accepted 7 November 2009; published online 9 February 2010
(aAbs) and might constitute a potential target for antibody-specific immunotherapy. Thyroperoxidase is one of the major autoantigens involved in autoimmune thyroid diseases (AITD), such as Hashimoto's thyroiditis (McLachlan and Rapoport, 1992, 2000). Hashimoto's thyroiditis is characterised by glandular hypofunction, destruction of thyroid cells and production of an immunoglobulin G (IgG) response directed against TPO. AntiTPO aAbs are invaluable markers of thyroid autoimmune response and have been shown to exert both in vitro and in vivo cytotoxic functions such as C3 complement activation (Wadeleux et al, 1989; Chiovato et al, 1993; Parkes et al, 1994) and antibody-dependent cell-mediated cytotoxicity (ADCC) (Bogner et al, 1989; Rodien et al, 1996; Guo et al, 1997; Metcalfe et al, 1997; Rebuffat et al, 2008). These effects probably participate in the maintenance and amplification of thyroid cell destruction in Hashimoto's disease. On the basis of these observations, one could envision the use of anti-TPO aAbs as potential antigen-specific agents with cytotoxic activities for the treatment of thyroid carcinomas.

In addition, it is well known that in AITD such as Hashimoto's disease, lymphocytes infiltrate and destroy thyroid gland. Previous reports have suggested that the immune system attempts to control cancer thyroid cells. Indeed, lymphocytes as well as monocytes/ macrophages are often found in the periphery or infiltrated in the tumours, which make them potential effectors involved in the destruction of cancer cells. 
Using the phage-display technology, we previously selected and characterised human recombinant anti-TPO aAbs (Chapal et al, 2000, 2001). These human recombinant anti-TPO aAbs mimic human anti-TPO aAbs present in the sera of patients suffering from AITD and recognise the human TPO (hTPO) immunodominant region (Bresson et al, 2003, 2004, 2005, Rebuffat et al, 2006). To evaluate if these anti-TPO aAbs may be useful tools in the treatment of thyroid carcinomas, we selected a human recombinant anti-TPO aAb and expressed it in baculovirus (B4) and in $\mathrm{CHO}$ cells $\left(\mathrm{B}^{\prime}\right)$. We explored their biological properties in vitro before future in vivo preclinical tests. Cytotoxic activity, complement-dependent cytotoxicity (CDC) and ADCC, of purified human recombinant anti-TPO aAbs (B4 and B4') expressed in respectively baculovirus and $\mathrm{CHO}$ cells, were studied on thyroid carcinoma cells and compared with those of circulating anti-TPO aAbs purified from the sera of patients suffering from AITD, using the same target cells. We show here that anti-TPO aAb B4 ${ }^{\prime}$ purified from $\mathrm{CHO}$ is able to induce a moderate cytotoxic activity, lower than that of patients' circulating anti-TPO aAbs on the papillary carcinoma cell line NPA, whatever the effector cells used (peripheral blood mononuclear cells (PBMC) or monocyte cell line). However, neither human recombinant anti-TPO aAbs B4 purified from baculovirus/insect cells nor deglycosylated aAbs from patients' sera appear able to induce any significant CDC, ADCC or anti-proliferative activity.

\section{MATERIALS AND METHODS}

\section{Reagents}

Human recombinant anti-TPO scFv antibody $\mathrm{B}_{4}$ was selected in our laboratory using a phage-display library and expressed as $\operatorname{IgG}_{1}$ in baculovirus/insect cells system by Dr M Cerutti as previously described (Bresson et al, 2001, 2003). Sera from patients suffering from Graves' disease were obtained from Dr B Guerrier (Guy de Chauliac Hospital, Montpellier, France) and Dr L Baldet (Lapeyronie University Hospital, Montpellier, France). IgG 1 antibodies were purified on a protein $\mathrm{G}$ affinity column and the concentration determined by absorbance at $280 \mathrm{~nm}, \mathrm{E}^{0.1 \%}$ of 1.40 . Human sera anti-TPO aAbs were deglycosylated using the Dig Glycan differentiation kit (Roche, Basel, Switzerland). Mouse monoclonal anti-hTPO antibodies mAb15 and mAb47 were provided by Dr J Ruf (INSERM Unit 555, Marseille, France). Human TPO, purified (more than $95 \%$ pure) from thyroid glands, was obtained from HyTest Ltd (Turku, Finland).

\section{Cells}

Human anaplastic thyroid cancer cell lines SW1736 and C643 (Mark et al, 1987) were kindly provided by Dr NE Heldin, Denmark, and human follicular thyroid cancer cell lines ML1 (Schonberger et al, 2000) and WRO (Estour et al, 1989) were from J Schonberger. The human papillary thyroid cancer cell line NPA was a gift from Professor Santoro, Italy (Fagin et al, 1993). Cells were cultured in RMPI 1640 (Cambrex, Belgium) containing $10 \%$ fetal calf serum (FCS) (PAA Laboratories, Linz, Austria), $2 \mu \mathrm{M}$ L-glutamine, $100 \mathrm{U} \mathrm{ml}^{-1}$ of penicillin and $100 \mu \mathrm{g} \mathrm{ml}^{-1}$ of streptomycin (Life Technologies Inc., Paisley, UK).

Peripheral blood mononuclear cells obtained from healthy donors (Etablissement Français du Sang, Montpellier, France) were separated from blood by Ficoll density gradient (Histopaque1077; Sigma-Aldrich, St Louis, MO, USA) and resuspended in RPMI 1640 supplemented with $10 \%$ heat-inactivated FCS, $50 \mathrm{U} \mathrm{ml}^{-1}$ penicillin, $50 \mu \mathrm{g} \mathrm{ml}^{-1}$ streptomycin and $2 \mathrm{mmoll}^{-1}$ glutamine.

The 11A1.6 $\mathrm{CD}^{+}{ }^{+}$(van Vugt et al, 1999), CDw32-L CD32 ${ }^{+}$ (Peltz et al, 1988) and Jurkat CD16 ${ }^{+}$(Vivier et al, 1992) cell lines were kindly provided by Professor J van de Winkel, Dr J Lewsen (Immunotherapy Laboratory, Utrech University, The Netherlands), Dr JP Vendrell (Virology Laboratory, University Hospital, Montpellier, France) and Professor E Vivier (INSERM U608, Marseille, France) respectively.

The effector cell line (HL-60), a human monocyte line (provided by J Dornand, Montpellier), was grown in the same medium as PBMC. Five days before the experiment, 1,25-dihydroxyvitamin $\mathrm{D}_{3}$ $\left(1,25(\mathrm{OH})_{2} \mathrm{D}_{3}\right)\left(=\mathrm{D}_{3}\right.$ vitamin) was added to induce differentiation of HL-60 cells into monocytes. All cell cultures were incubated at $37^{\circ} \mathrm{C}$ in a humidified atmosphere containing $5 \% \mathrm{CO}_{2}$. Methotrexate ( $5 \mu \mathrm{M}$; Sigma-Aldrich) and geneticin (G418) $\left(0.5 \mathrm{mg} \mathrm{ml}^{-1}\right.$; Sigma-Aldrich) were added, respectively, to $11 \mathrm{~A} .6 \mathrm{CD}^{+} 4^{+}$and Jurkat $\mathrm{CD}_{16}{ }^{+}$cell lines.

The expression of CD14, CD16 (Fc $\gamma$ RIII), CD32 (Fc $\gamma$ RII), CD64 $(\mathrm{F} c \gamma \mathrm{RI})$ on the surface of the different effector cells (HL-60 and PBMC) was investigated using fluorescein-conjugated anti-human $\mathrm{CD} \mathrm{Ab}$ (Miltenyi Biotech, Bergisch Gladbach, Germany and Pharmingen, Becton Dickinson, Franklin Lakes, NJ, USA) and analysed by flow cytometry analysis as previously described (Rebuffat et al, 2008). Monocytes and lymphocytes present in PBMC were identified by size/structure analysis.

\section{Expression and production of recombinant human anti-TPO antibody in CHO cells}

The recombinant human anti-TPO scFv B4 was selected from an antibody phage-display library obtained from B cells extracted from thyroid tissue of patients suffering from Graves' disease (Chapal et al, 2001). ScFv B4 was expressed as a whole $\mathrm{IgG}_{1}$ antibody in the baculovirus/insect cell system (anti-TPO recombinant $\mathrm{aAb} \mathrm{B} 4)$. To improve glycosylation of the $\mathrm{Fc}$ part of this recombinant antibody, we also expressed $s c F v$ B4 as an $I_{g G}$ in the $\mathrm{CHO}$ eukaryote system (anti-TPO recombinant $\mathrm{aAb} \mathrm{B}^{\prime}$ ). The variable heavy chain of $\mathrm{B} 4$ was cloned between BamHI and NheI restriction sites in the plasmid vector pcDNA3 (Invitrogen Life Technologies, Carlsbad, CA, USA) containing the sequence of the heavy chain $(\mathrm{pcDNA} 3 / \mathrm{H})$ and the variable light chain of $\mathrm{B} 4$ between BamHI and XhoI in another plasmid vector pcDNA3 containing the sequence of the light chain (pcDNA3/L). These two plasmid vectors were kindly provided by Stephane Birkle (AlvarezRueda et al, 2007). Expression plasmids pcDNA3/L and pcDNA3/H were transfected into $\mathrm{CHO}$ cells using a Polyfect Transfection Reagent kit (Qiagen $\mathrm{GmbH}$, Germany) according to the manufacturer's instructions. Cells were selected in the presence of $0.5 \mathrm{mg} \mathrm{ml}^{-1} \mathrm{G} 418$ and $0.5 \mathrm{mg} \mathrm{ml}^{-1}$ Zeocin (Invitrogen Life Technologies). Double-resistant clones were isolated by limiting dilution, and the supernatants of resistant transfectants screened by ELISA. The anti-TPO recombinant aAb $B 4^{\prime} \mathrm{IgG}_{1}$ was purified on a protein $\mathrm{G}$ affinity column and the concentration determined by measuring the absorbance at $280 \mathrm{~nm}, \mathrm{E}^{0.1 \%}$ of 1.40 .

\section{Flow cytometry analysis of TPO expression on the membrane of human thyroid cancer cell lines}

Cells were removed from the culture flasks using HEPES-EDTA

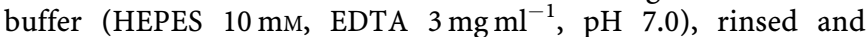
pelleted ( $5 \mathrm{~min}, 1000$ r.p.m., $4^{\circ} \mathrm{C}$ ) in Dulbecco's phosphate-buffered saline (D-PBS) (Cambrex) containing 2\% FCS (=F-buffer). Approximately $10^{6}$ cells were incubated with $200 \mu$ l of F-buffer containing $10 \mu \mathrm{g} \mathrm{ml}^{-1}$ of human anti-TPO aAb for $60 \mathrm{~min}$ at $4{ }^{\circ} \mathrm{C}$, then washed twice and further incubated in $200 \mu \mathrm{l}$ of F-buffer containing $10 \mu \mathrm{g} \mathrm{ml}^{-1}$ of fluorescein-conjugated anti-human IgG $\gamma$-chain-specific $\mathrm{Ab}$ (Sigma-Aldrich) for $60 \mathrm{~min}$ at $4{ }^{\circ} \mathrm{C}$ in the dark. Negative controls were performed by incubating cells with only the secondary antibody. After two washings with D-PBS, the cells were analysed (10000 events) with an EPICS XL4 (Beckman-Coulter, Fullerton, CA, USA) fluocytometer. 
Flow cytometry analysis of human anti-TPO antibodies bound to TPO expressed on the membrane of NPA cells

Flow cytometry analysis was carried out as previously described. NPA cells $\left(\sim 10^{6}\right)$ were incubated with human anti-TPO aAb (B4, $B 4^{\prime}$ or purified from sera of patients suffering from AITD); the reaction was revealed with a secondary antibody and analysed with an EPICS XL4 fluocytometer.

\section{Flow cytometric analysis of human anti-TPO antibodies bound to the $\mathrm{F} c \gamma \mathrm{R}$}

Cells expressing specifically one $\mathrm{Fc} \gamma \mathrm{R}$ and effector cells (PBMC and HL-60) were rinsed and pelleted ( $5 \mathrm{~min}, 1000$ r.p.m., $4{ }^{\circ} \mathrm{C}$ ) in F-buffer. The cells $\left(\sim 10^{6}\right)$ were incubated for $90 \mathrm{~min}$ at $4^{\circ} \mathrm{C}$ with $200 \mu \mathrm{l}$ of F-buffer containing $10 \mu \mathrm{g} \mathrm{ml}^{-1}$ of the complex $\mathrm{TPO} /$ human anti-TPO aAb (B4, B4 ${ }^{\prime}$ and aAbs purified from sera of patients suffering from AITD, preliminary incubated with hTPO (HyTest Ltd) for $45 \mathrm{~min}$ at $4^{\circ} \mathrm{C}$ ). They were then washed, incubated with $10 \mu \mathrm{g} \mathrm{ml}^{-1}$ of fluorescein-conjugated anti-human IgG $\gamma$-chain-specific antibody and binding analysed as previously described.

\section{In vitro antibody-dependent cell-mediated cytotoxicity assay}

Antibody-dependent cell-mediated cytotoxicity assays were carried out using the standard ${ }^{51} \mathrm{Cr}$ release assay (Rebuffat et al, 2008). Target cells (NPA cell line) were removed from culture flasks using HEPES - EDTA buffer, rinsed and aliquots $\left(\sim 10^{6}\right.$ cells) incubated $\left(37^{\circ} \mathrm{C}, 60 \mathrm{~min}, 5 \% \mathrm{CO}_{2}\right)$ in culture medium $100 \mu \mathrm{Ci}^{51} \mathrm{Cr}$. Cells were then washed to eliminate unincorporated ${ }^{51} \mathrm{Cr}$ and labelled target cells incubated $\left(4^{\circ} \mathrm{C}, 45 \mathrm{~min}\right)$ with human anti-TPO antibodies (B4 and $\mathrm{B}^{\prime}$ or aAbs purified from sera of patients suffering from AITD) $\left(50 \mu \mathrm{g} \mathrm{ml}^{-1}\right)$. They were then seeded $\left(2 \times 10^{4}\right.$ cells per well $)$ in 96-well U-bottomed culture plates and incubated with effector cells (effector/target ratio, 50:1 PBMC, 12:1 HL-60). As controls, Jurkat cells were submitted to the same conditions than NPA cells and an irrelevant human IgG from healthy subjects or culture medium alone were used. Target cells were used to determine spontaneous ${ }^{51} \mathrm{Cr}$ released in culture medium only and total ${ }^{51} \mathrm{Cr}$ release was assessed by addition of $\mathrm{HCl}(1 \mathrm{~N})$. Tests and controls were performed in triplicate. Cells were incubated for $6 \mathrm{~h}\left(37^{\circ} \mathrm{C}\right.$, $\left.5 \% \mathrm{CO}_{2}\right)$, centrifuged ( $\left.5 \mathrm{~min}, 1000 \mathrm{~g}\right)$ and aliquots $(100 \mu \mathrm{l})$ sampled for $\gamma$-counting. Cytotoxicity was expressed as specific ${ }^{51} \mathrm{Cr}$ release calculated as follows: Lysis $=(($ c.p.m. with effector cells $)-$ (c.p.m. with culture medium $)) /($ (c.p.m. with $\mathrm{HCl})-($ c.p.m. with culture medium)).

\section{Complement fixation assay}

To study the ability of TPO/anti-TPO antibody complexes to bind to $\mathrm{Clq}$ complement, microtitre plates were coated with $\mathrm{TPO} / \mathrm{anti}$ TPO aAbs (B4 and B4' and aAbs purified from patients' sera) complexes, in $100 \mathrm{~mm} \mathrm{NaHCO}_{3}(\mathrm{pH} 9.0)$ at $4{ }^{\circ} \mathrm{C}$ overnight. The plates were washed three times with D-PBS-Tween $0.1 \%$ and blocked with $1 \%$ non-fat powdered milk in D-PBS-Tween $0.1 \%$ (blocking buffer) for $60 \mathrm{~min}$ at $37^{\circ} \mathrm{C}$. After washing, $\mathrm{C} 1 \mathrm{q}$ complement was incubated in the blocking buffer for $90 \mathrm{~min}$ at $37^{\circ} \mathrm{C}$. Plates were then washed and anti-Clq antibody was added for $60 \mathrm{~min}$ at $37^{\circ} \mathrm{C}$. After washing, peroxidase-conjugated antimouse IgG (diluted 1:1000 in the blocking buffer) was incubated for $60 \mathrm{~min}$ at $37^{\circ} \mathrm{C}$. After three washings, binding of $\mathrm{C} 1 \mathrm{q}$ to antiTPO aAb was detected by addition of $4 \mathrm{mg} \mathrm{ml}^{-1} 2$-phenylenediamine solution containing $0.03 \%(\mathrm{v} / \mathrm{v})$ hydrogen peroxide in $0.1 \mathrm{M}$ citrate buffer ( $\mathrm{pH}$ 5.0). The reaction was stopped with $2 \mathrm{M} \mathrm{H}_{2} \mathrm{SO}_{4}$ and the resulting absorbance measured at $490 \mathrm{~nm}$.

\section{In vitro complement-dependent cytotoxicity assay}

To test complement-mediated cytotoxicity, NPA cells $\left(10^{6}\right)$ were labelled with $100 \mu \mathrm{Ci}{ }^{51} \mathrm{Cr}$ for $60 \mathrm{~min}$ at $37^{\circ} \mathrm{C}$. After washing, labelled target cells were distributed $\left(2 \times 10^{4}\right.$ cells per well) in 96-well U-bottomed culture plates. Target cells (triplicate wells) were incubated $\left(4^{\circ} \mathrm{C}, 45 \mathrm{~min}\right)$ in culture medium in the absence or presence of an anti-TPO aAb $\left(50 \mu \mathrm{g} \mathrm{ml}^{-1}\right)$ (recombinant B4, B4', aAbs purified from sera of patients suffering from AITD or monoclonal antibodies (mAb15 and mAb59) known to target two different regions on TPO surface (Ruf et al, 1989)). Cells were incubated for $4 \mathrm{~h}$ at $37^{\circ} \mathrm{C}$, with a source of Complement (guinea pig serum; Sigma-Aldrich). After centrifugation (5 min, $1000 \mathrm{~g})$, aliquots $(100 \mu \mathrm{l})$ of the supernatant were sampled for $\gamma$-counting. Cytotoxicity was expressed and calculated as previously described.

\section{Papillary thyroid cancer cell proliferation assay}

NPA cell growth was assessed after 5 days of culture using the cell bromodeoxyuridine (BrdU) proliferation kit (Roche) according to the manufacturer's instructions. NPA cells were cultured in triplicate in 96-well culture microplates at $2 \times 10^{4}$ cells per well (Techno plastic products, Trasadingen, Switzerland) in $200 \mu \mathrm{l}$ of culture medium in the absence or presence of $50 \mu \mathrm{g} \mathrm{ml}^{-1}$ of antiTPO recombinant aAbs (B4 or $\mathrm{B}^{\prime}$ ) or anti-TPO aAbs from patients' sera used as inhibitors. Microplates were then incubated for 4 days at $37^{\circ} \mathrm{C}$ in a wet atmosphere containing $5 \% \mathrm{CO}_{2}$. Bromodeoxyuridine 1:100 dilution was then added, and microplates incubated for an additional $24 \mathrm{~h}$. Bromodeoxyuridine incorporation was measured using a horseradish peroxidaseconjugated anti-BrdU antibody and $o$-phenylenediamine $(100 \mu \mathrm{l}$ per well) as substrate. The colorimetric reaction was stopped by addition of $50 \mu \mathrm{l}$ of $4 \mathrm{~N}$ sulphuric acid per well and absorbance measured at $490 \mathrm{~nm}$.

\section{RESULTS}

\section{Thyroid cancer and effector cell lines characterisation}

Before testing the potential use of anti-TPO aAbs for immunotherapy of thyroid cancer by cytotoxic assays (ADCC and CDC), we first characterised the target and effector cells. Expression of thyroperoxidase was investigated in five potential target cells, human anaplastic (SW1736 and C643), follicular (ML1 and WRO) and papillary (NPA) thyroid cancer cell lines. Thyroperoxidase was found to be expressed in $100 \%$ of papillary thyroid cells line (NPA) $v s$ in only 43 and $69 \%$ of, respectively, ML1 and WRO follicular thyroid cancer cells. As expected human anaplastic cancer cells (SW1736 and C643) poorly expressed TPO on their cell surface (Figure 1A). Various populations of effector cells exert different functions by FcR-mediated antibody-antigen binding. Fc $\gamma$ RI (CD64) (the high-affinity IgG receptor), Fc $\gamma$ RIIa (CD32) and Fc $\gamma$ RIII (CD16) (the low-affinity IgG receptor) are activating receptors present on a wide range of myeloid cells (monocytes, macrophages, dendritic cells, neutrophils and natural killer (NK) cells). As we previously showed (Rebuffat et al, 2008) that monocytes are potential effector cells in AITD, the monocyte cell line HL-60 and PBMC were chosen as effector cells for cytotoxic assays. We characterised these cells regarding monocytes surface markers such as $\mathrm{CD} 14$ and $\mathrm{Fc} \gamma \mathrm{R}$ expression. The differentiation of HL-60 into monocytes with $\mathrm{D}_{3}$ vitamin was assessed by determining CD14 expression (98.26\%). Flow cytometry analysis showed that Fc $\gamma$ RII (CD32) and Fc $\gamma$ RI (CD64) are expressed on the HL-60 cell line and on the monocyte population present in PBMC (more than 90\% of cells were stained). On the other hand, Fc $\gamma$ RIII (CD16) was only present on 


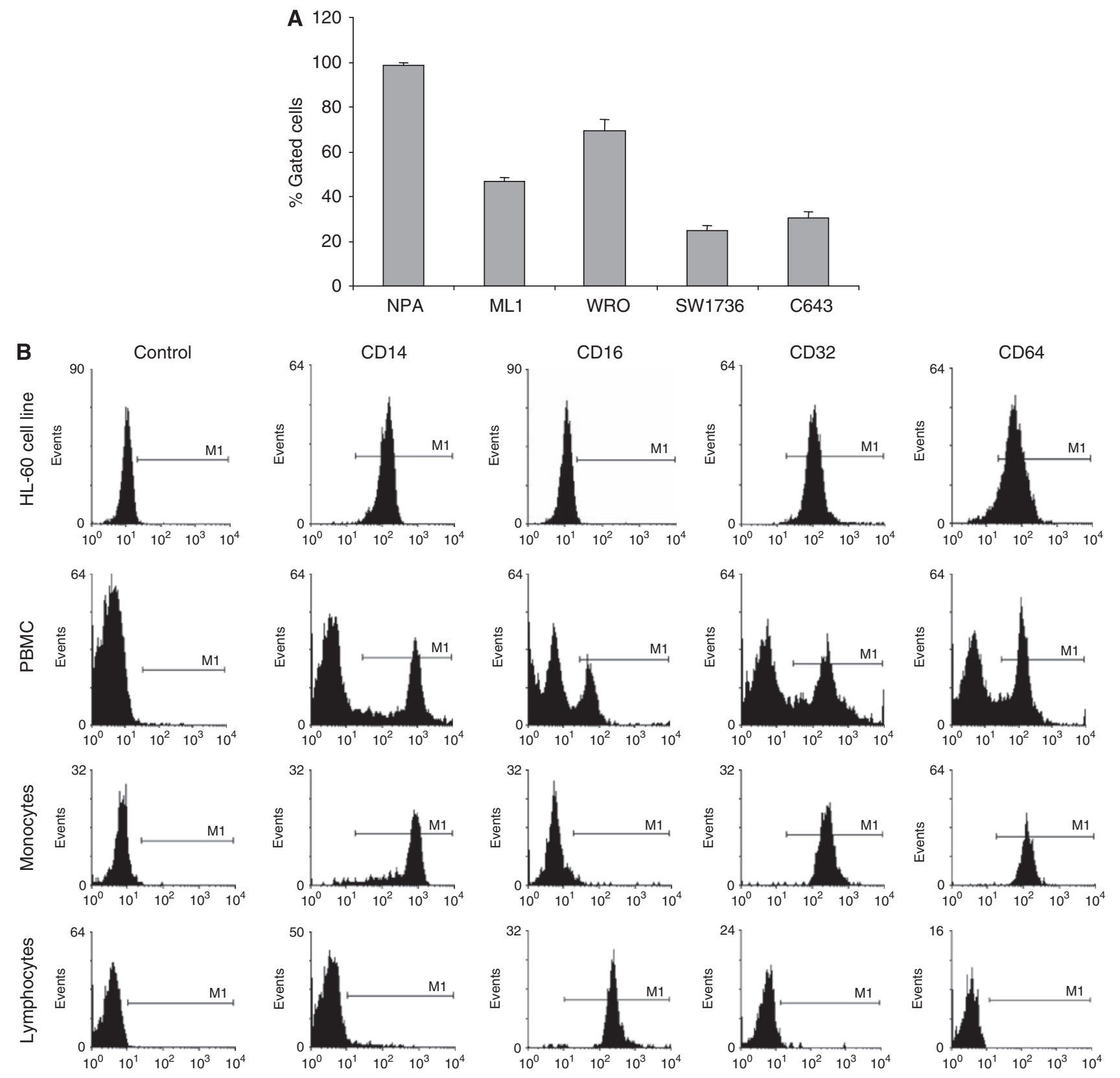

Figure I Thyroid cancer and effector cell lines characterisation. (A) TPO expression was investigated by flow cytometry on papillary (NPA), follicular (MLI and WRO) and anaplastic thyroid cancer (SWI736 and C643) cell lines. Cells were incubated successively with a human anti-TPO antibody and with an anti-human FITC antibody. Data correspond to the average of two experiments. (B) Expression of four specific markers (CDI4, CDI6, CD32 and CD64) was studied on effector cells: peripheral blood mononuclear cells (entire PBMC, lymphocytes and monocytes) and a monocyte cell line (HL-60). CDI4 is only expressed on monocytes; Fcy receptors CDI 6 on lymphocytes, CD32 and CD64 on monocytes. Conjugated controls show no background staining.

the lymphocyte population of PBMC and more specifically on NK cells (Figure 1B).

Human recombinant anti-TPO aAbs B4, B4' and patients' sera exhibit different binding properties to $\mathrm{Fc} \gamma \mathrm{Rs}$ and ADCC activity

Before studying the ability of human recombinant anti-TPO aAbs B4 and B4' and affinity purified IgG from patients' sera to mediate ADCC, we evaluated their binding capacity. Therefore, we measured binding of aAbs to TPO expressed on NPA cells (Figure 2A), and binding of TPO/anti-TPO complexes on Fc $\gamma \mathrm{RI}$
(CD64), Fc $\gamma$ RII (CD32) and Fc $\gamma$ RIII (CD16) expressed by both CD cell lines (Figure 2B) and effector cells (Figure $3 \mathrm{~A}$ and $\mathrm{B}$ ). As indicated in Figure 2A, similar cytometry patterns, showing the binding of anti-TPO aAbs on NPA target cells, occurred with human recombinant anti-TPO aAbs B4 and B4' (91.96 and 98.77\%, respectively). This shows that the expression system used for the anti-TPO aAb (baculovirus/insect cell or in CHO cell) does not modify specificity of the aAb. Furthermore, anti-TPO aAbs purified from patients' sera, which are polyclonal and recognise different epitopes on the TPO molecule, exhibit a comparable binding profile $(99.97 \%$ of stained cells). The reactivity of complexes of the human recombinant anti-TPO aAbs and patients' 


\section{Control}

Anti-TPO

recombinant $A b$

(B4)
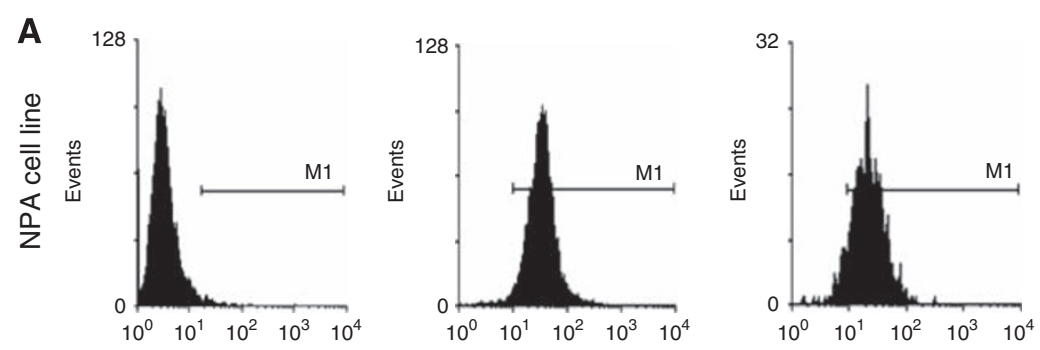

Anti-TPO

recombinant $\mathrm{Ab}$

(B4')
Anti-TPO Ab

from patient

with AITD
Deglycosilated

anti-TPO Ab

from patient

with AITD

B
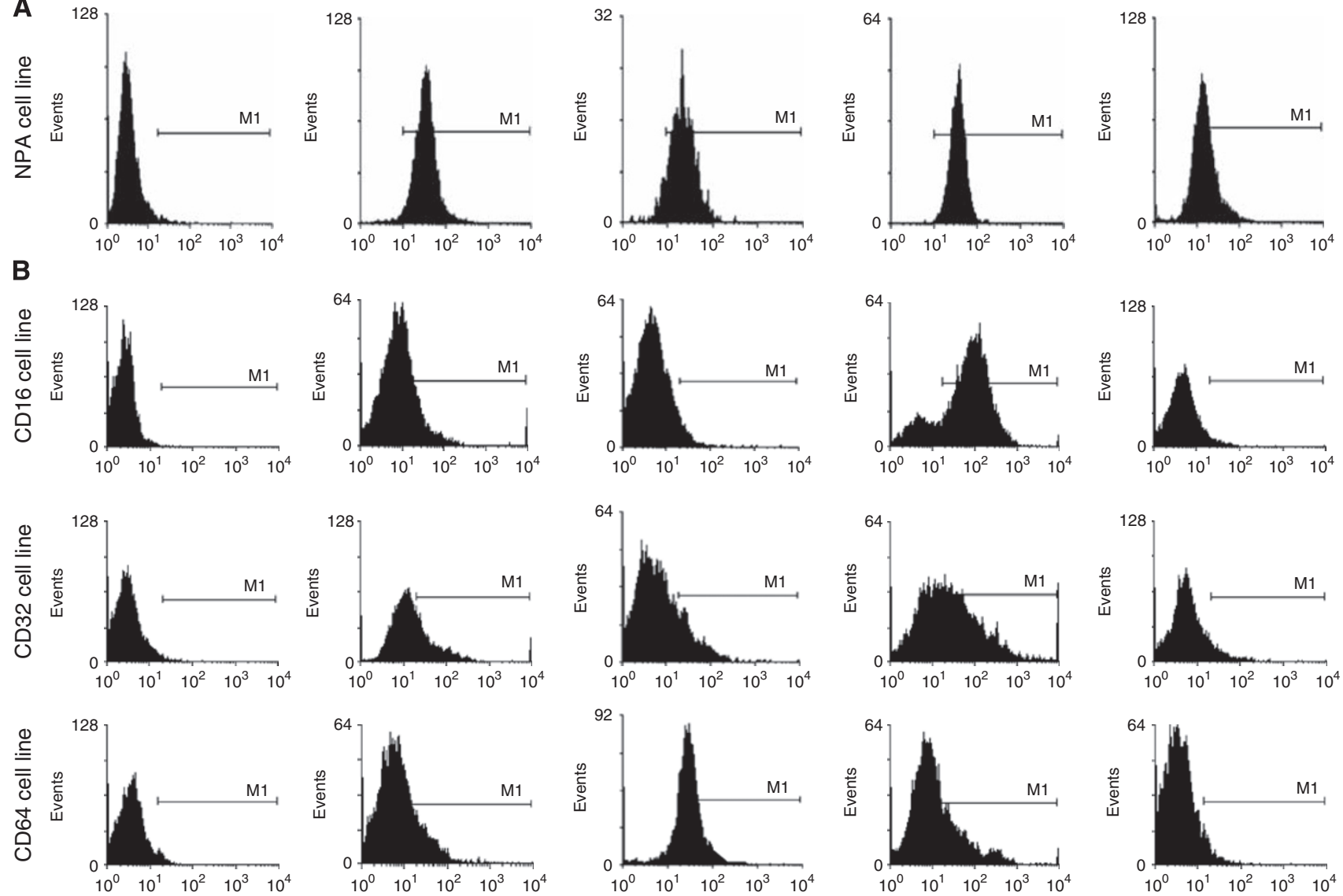

Figure 2 Binding capacity of human recombinant anti-TPO aAbs. (A) Three different human recombinant anti-TPO aAbs (anti-TPO aAbs expressed in baculovirus (B4), in $\mathrm{CHO}$ (B4') and patients' sera) were analysed by flow cytometry for their ability to bind to the NPA cell line. (B) Binding of TPO/antiTPO complexes on FcyRl (CD64), FcyRll (CD32) and FcyRlll (CDI6) expressed by CD cell lines has been analysed by flow cytometry.

sera with TPO was analysed using cell lines 11A1.6 $\mathrm{CD}^{+} 4^{+}$, $\mathrm{CDw} 32-\mathrm{L} \mathrm{CD}_{2}{ }^{+}$and Jurkat $\mathrm{CD} 16^{+}$, which express only one type of $\mathrm{Fc} \gamma \mathrm{R}$ (CD16, CD32 or CD64). Only anti-TPO aAbs from patients' sera were able to bind the three types of $\mathrm{Fc} \gamma \mathrm{Rs}$ with a staining value of $30.99,54.21$ and $81.69 \%$ for CD64, CD32 and CD16, respectively. The two human recombinant anti-TPO aAbs (B4 and $\mathrm{B}^{\prime}$ ) exhibited no major differences in binding profile for CD32 and CD16. However, B4' exhibited a stronger binding affinity than B4 (83.19 vs 22.66\%) for CD64 (Figure 2B). An anti-Fc $\gamma$ Rs Ab, used as control, abolished the binding of the immune complex to the effector cells and confirmed that binding of human anti-TPO aAbs involves their $\mathrm{Fc}$ region (data not shown). Finally, if $\mathrm{Ab}$ deglycosylation only moderately alters antigen binding, it significantly modifies the binding of $\mathrm{Fc} \gamma \mathrm{R}$ on human cell lines (Figure $2 \mathrm{~B}$ ). Taken together, these data suggest that the TPO-antiTPO aAbs were able to bind $\mathrm{Fc} \gamma \mathrm{R}$ of cell lines expressing CD16, CD32 and CD64 (Figure 2B).

The next step was to examine the binding of these complexes on effector cells, lymphocyte and monocyte populations present in PBMC as well as HL-60 cells used in ADCC assays. The anti-TPO aAbs (patients' sera, B4 and B4') bound HL-60 cells by their FC domain (Figure $3 \mathrm{~A}$ ). However, binding of the aAbs on PBMC showed different patterns due to the level of Fc $\gamma$ Rs expression on these cell populations. The anti-TPO aAbs purified from patients' sera and B4 expressed in baculovirus/insect cell system, which appeared able to bind the three $\mathrm{F} c \gamma \mathrm{R}$ types (Figure $3 \mathrm{~B}$ ), strongly interacted with the monocyte and lymphocyte populations present in PBMC. In contrast, the human recombinant anti-TPO aAbs expressed in $\mathrm{CHO}$ cells $\left(\mathrm{B}^{\prime}\right)$ bound $90 \%$ of the monocyte population but only $40 \%$ of the lymphocyte population (most probably NK cell lymphocytes). Thereafter, the ability of recombinant and circulating anti-TPO aAbs to lyse papillary thyroid cancer cells was explored using systems detecting ADCC with the monocyte cell line HL-60 and PBMC as effector cells and NPA cells as targets, because $100 \%$ of these cells express TPO on their cell surface. The capacity of recombinant anti-TPO aAbs (B4 and $\mathrm{B}^{\prime}$ ) and purified aAbs from patients' sera to exhibit ADCC was tested (Figure 3C). Anti-TPO aAbs purified from patients' sera lysed $24-29 \%$ of NPA cells, whereas the human recombinant antiTPO aAbs were less effective (B4 $(3.5-10 \%)$ and B4' $(9-19.5 \%))$. It is worth noting that Jurkat cells, used as a control, were insensitive to anti-TPO aAbs, showing the specificity of these antibodies to lyse NPA cells. Interestingly, whatever the aAbs used (patients' sera, B4 or $\mathrm{B}^{\prime}$ ), a greater ADCC efficiency was obtained with PBMC than with the monocyte cell (29\% for PBMC vs $24 \%$ for HL$60)$. This result is in accordance with the expression by PBMC of three types of $\mathrm{Fc} \gamma \mathrm{Rs}$ (CD16 on lymphocytes NK cells, CD32 and CD64 on monocytes) whereas monocyte cells HL-60 express only Fc $\gamma$ RI (CD64) and Fc $\gamma$ RII (CD32). From the comparison of the ADCC activity of the different anti-TPO aAbs, it appears that the 
A Anti-TPO
Control
Ab (B4)

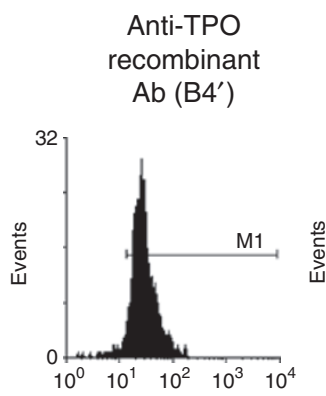

Anti-TPO

Anti-TPO recombinant $A b$

(B4)
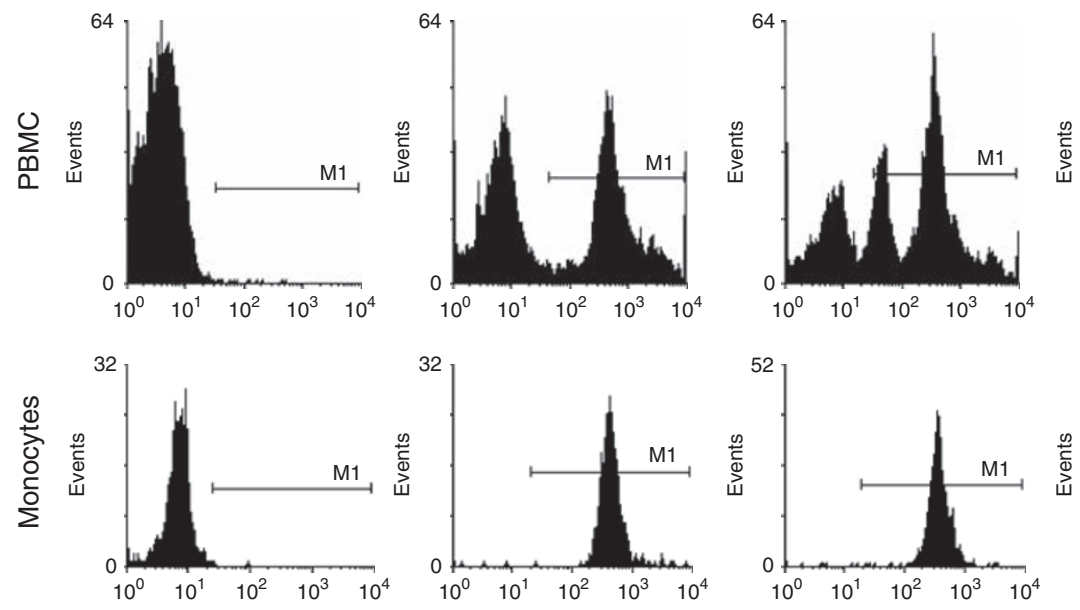

(B4')
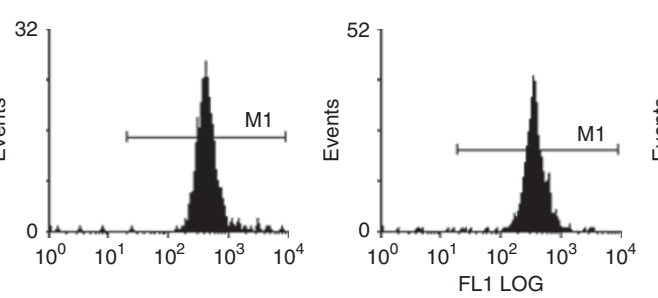

Anti-TPO Ab

from patient with AITD
Deglycosilated

anti-TPO Ab

from patient with AITD
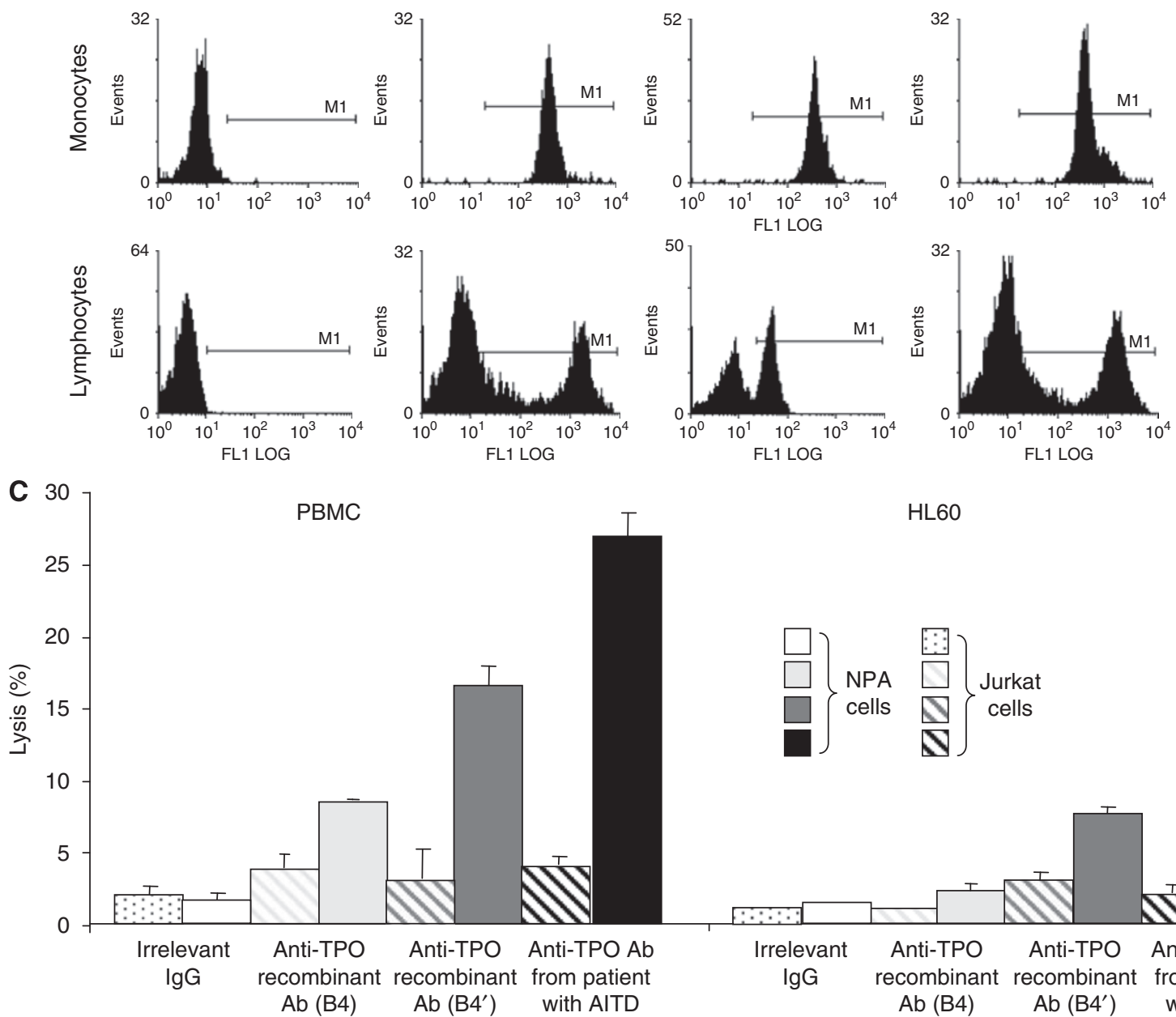

$\mathrm{Ab}(\mathrm{B} 4)$

$\mathrm{Ab}\left(\mathrm{B} 4^{\prime}\right)$

with AITD
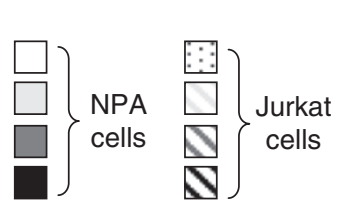

Figure 3 Antibodies-dependent cellular cytotoxicity (ADCC) mediated by human recombinant anti-TPO aAbs (B4 and B4') and patient's sera anti-TPO aAbs. (A and B) Binding of TPO/anti-TPO complexes on effector cells (HL-60 cell line and PBMC) was analysed by flow cytometry. (C) Antibodiesdependent cellular cytotoxicity was determined by the ${ }^{51} \mathrm{Cr}$ release assay. Human thyroid cells were incubated with irrelevant Abs ( $\square$ ) or human anti-TPO aAbs purified from sera of patients suffering from AITD ( , B4 ( $\square$ and B4' ( $\square$ with different effector cells (PBMC and HL-60). Y axis presents the percentage of Jurkat $(\square$ or NPA cells $(\mathbb{D})$ lysis. Bars, s.d. Results are mean of triplicates. 
anti-TPO aAbs purified from patients' sera were more efficient than the recombinant aAbs expressed in $\mathrm{CHO}$ system $\left(\mathrm{B}^{\prime}\right)$ and finally the anti-TPO aAbs expressed in baculovirus/insect cell system (B4). This shows once again that the carbohydrate residues are crucial for the cytotoxic activity of the Abs.

\section{Human recombinants anti-TPO aAbs $\mathrm{B} 4, \mathrm{~B} 4{ }^{\prime}$ and patients' sera mediate CDC on NPA cells}

Activation of the Complement membrane attack complex (MAC; C5b-9) can lead to direct lysis of target cells by complementdependent cytotoxicity (CDC). This can occur by the classical pathway with the $\mathrm{C} 1$ component, after binding of antibodies to the target cells. To determine whether human recombinants and patients' sera anti-TPO aAbs act through a CDC mechanism on NPA cells, we investigated if C1q component binds to the immune complex anti-TPO aAbs/TPO. As expected, our ELISA data show that $\mathrm{C} 1 \mathrm{q}$ does bind to the different complexes (Figure $4 \mathrm{~A}$ ). In contrast, an irrelevant IgG used as control failed to bind the C1q. As tumour cells often evade complement activation because they express membrane-bound complement regulatory proteins, we investigated the relative surface expression of three of the main complement regulatory proteins: CD46 (membrane cofactor protein), CD55 (decay-accelerating factor) and CD59 (protecting) by flow cytometry on NPA cells (Figure 4B). NPA cells expressed all the three proteins, with a greater expression of CD59 and CD55 than CD46 proteins, suggesting that NPA tumour cells were obviously protected against CDC. The ability of Complement to destroy papillary tumour cells was investigated. About $34 \%$ of cell lysis (Figure 4C1) was observed when ${ }^{51} \mathrm{Cr}$-labelled NPA cells were incubated with human anti-TPO aAbs purified from patients' sera and guinea pig serum. A lower CDC was observed with recombinant anti-TPO aAbs $\mathrm{B}^{\prime}{ }^{\prime}$ (9\% of cell lysis), whereas no complement cytotoxic activity was detected using recombinant anti-TPO aAbs B4. Finally, with regard to the CDC activity for the three human (recombinants and patients' sera) anti-TPO aAbs, we used two mAbs (mAb15 and mAb59) directed against two distinct epitopes on the TPO molecule to determine if the epitope recognition by anti-TPO Abs affects CDC mechanism. Figure 4C2 shows a weak and similar CDC with both mAb15 and mAb59 (7 and 9\% cell lysis, respectively) showing that, in our case, the epitopic recognition has no function in anti-TPO Abs CDC activity; thus differences observed between anti-TPO aAbs (B4, B4' and patients' sera) could be due to the polyclonality of the latter.

\section{Anti-TPO aAbs partially inhibit NPA cells proliferation}

The growth of NPA cells cultured in the presence of the anti-TPO recombinant aAbs (B4 and $\mathrm{B}^{\prime}$ ) and anti-TPO aAbs from sera of patients suffering from AITD was partially inhibited $(18,16$ and $25 \%$, respectively) but not in control cells cultured in medium alone (Figure 5).

\section{DISCUSSION}

We previously showed that TPO aAbs are, through both ADCC and CDC, able to damage human thyroid cells on binding to TPO expressed on the cell surface (Rebuffat et al, 2008). In this study, we hypothesised that human recombinant anti-TPO aAbs could be used to destroy thyroid tumour cells and thus to develop a complementary therapeutic approach in thyroid cancers. Before testing anti-TPO Abs in in vivo trials, we compared the in vitro cytotoxic activities of baculovirus-expressed, CHO-expressed human IgG1 anti-TPO aAbs named B4 and B4' with those of purified anti-TPO IgG of patients' sera, on papillary thyroid cancer cells expressing TPO. In this study, we show that anti-TPO aAbs, purified from patients' sera and CHO-expressing human recombinant $\mathrm{B} 4^{\prime}$ aAbs are able to induce moderate CDC, ADCC as well as anti-proliferative effects on NPA cells. In contrast baculovirusexpressing human recombinant B4 displayed no or only minor cytotoxic activities.

We focused this study, until now the only one, on the possible use of anti-TPO aAbs in thyroid cancer immunotherapy to improve the efficiency of conventional treatments and especially in carcinoma that do not respond to radioiodine therapy. In this respect the human anti-TPO aAbs (patients' sera and B4' aAbs expressed in $\mathrm{CHO}$ ) tested here exhibit some cytotoxic properties. Their specificity for TPO in targeting thyroid cancerous cell, their capacity to bind the $\mathrm{Clq}$ complement and their simultaneous recruitment of immune effector cells by binding to $\mathrm{Fc} \gamma \mathrm{R}$ through their Fc region agree with the concept that they could be considered as potential tools for passive immunotherapy.

If purified anti-TPO aAbs present in patients' sera, and to a lesser extend $\mathrm{B}^{\prime}$ (anti-TPO aAbs expressed in $\mathrm{CHO}$ ), mediate cytotoxic activity against thyroid cells, only partial or no effects were triggered by B4 (anti-TPO aAbs expressed in baculovirus). The low ADCC activities are probably due to the low glycosylation level of aAbs expressed in baculovirus. Indeed, the presence of specific oligosaccharide structures linked to the $\mathrm{C} \gamma 2$ domain of the $\mathrm{Fc}$ fragment has been reported to affect the biological activity of the antibody (Jefferis et al, 1998; Lifely et al, 1995; Wright and Morrison, 1997) by influencing the interaction with Fc $\gamma$ Rs (Tao and Morrison, 1989). In this context, biophysical and molecular studies have shown that $\mathrm{N}$-acetylglucosamine ( $\mathrm{GlcNac}$ ) in the triantennary $\mathrm{N}$-glycan seems also required to induce ADCC. The baculovirus-expressing system used does not incorporate GlcNac in proteins, which probably accounts for the lower cytotoxic activity mediated by the baculovirus-expressed anti-TPO aAb B4.

The biological responses triggered on $\mathrm{F} c \gamma$ Rs stimulation depend on the nature of cells expressing the receptor rather than on the receptor itself. Antibody-dependent cell-mediated cytotoxicity functions have been shown to be shared by various cell populations, including monocytes, NK cells and granulocytes (Ortaldo et al, 1987; Steplewski, 1993). Here, we used PBMC. A significant and more efficient $\mathrm{ADCC}$ has been obtained using human anti-TPO aAbs from patients' sera and PBMC. This result is probably due to (1) the use of correctly glycosylated Abs (as discussed above) and (2) the expression of all three types of Fc $\gamma$ Rs: Fc $\gamma$ RI (CD64), Fc $\gamma$ RII (CD32) and Fc $\gamma$ RIII (CD16) on the different cell populations in PBMC. Indeed, HL-60 cells express only Fc $\gamma \mathrm{RI}$ and Fc $\gamma$ RII, whereas PBMC include lymphocytes NK cells (bearing the Fc $\gamma$ RIII), monocytes and granulocytes (bearing Fc $\gamma$ RI and Fc $\gamma$ RII). These data show that anti-TPO aAbs are able to mediate higher ADCC with PBMC as effector cells.

Complement-dependent cytotoxicity activity depends on the binding of $\mathrm{Clq}$ on immune complexes and can be modulated by the presence on tumour cell of membrane-bound complementregulated proteins. All the anti-TPO aAbs we used bind to $\mathrm{Clq}$ but differences are observed in their CDC activity; a maximal efficiency is obtained using anti-TPO aAbs purified from patients' sera. One possible explanation is the polyclonality of the anti-TPO aAbs purified from patients' sera resulting in (1) recognition of a larger number of epitopes of TPO on target cells and (2) deposition of an increased number of complement fragments on these tumour cells, after activation of the complement system. Furthermore, in classical complement activation pathway, CD55 (Bjorge et al, 1997) and CD59 (Brasoveanu et al, 1996; Gorter et al, 1996) have the most prominent function in regulating the MAC, thus preventing cell lysis. These regulatory proteins are expressed on NPA cell membrane and probably partially protect them from CDC. Combining the various human recombinants anti-TPO aAbs we selected by phage display and characterised in term of epitopes (Bresson et al, 2003, 2004; Chapal et al, 2000; 

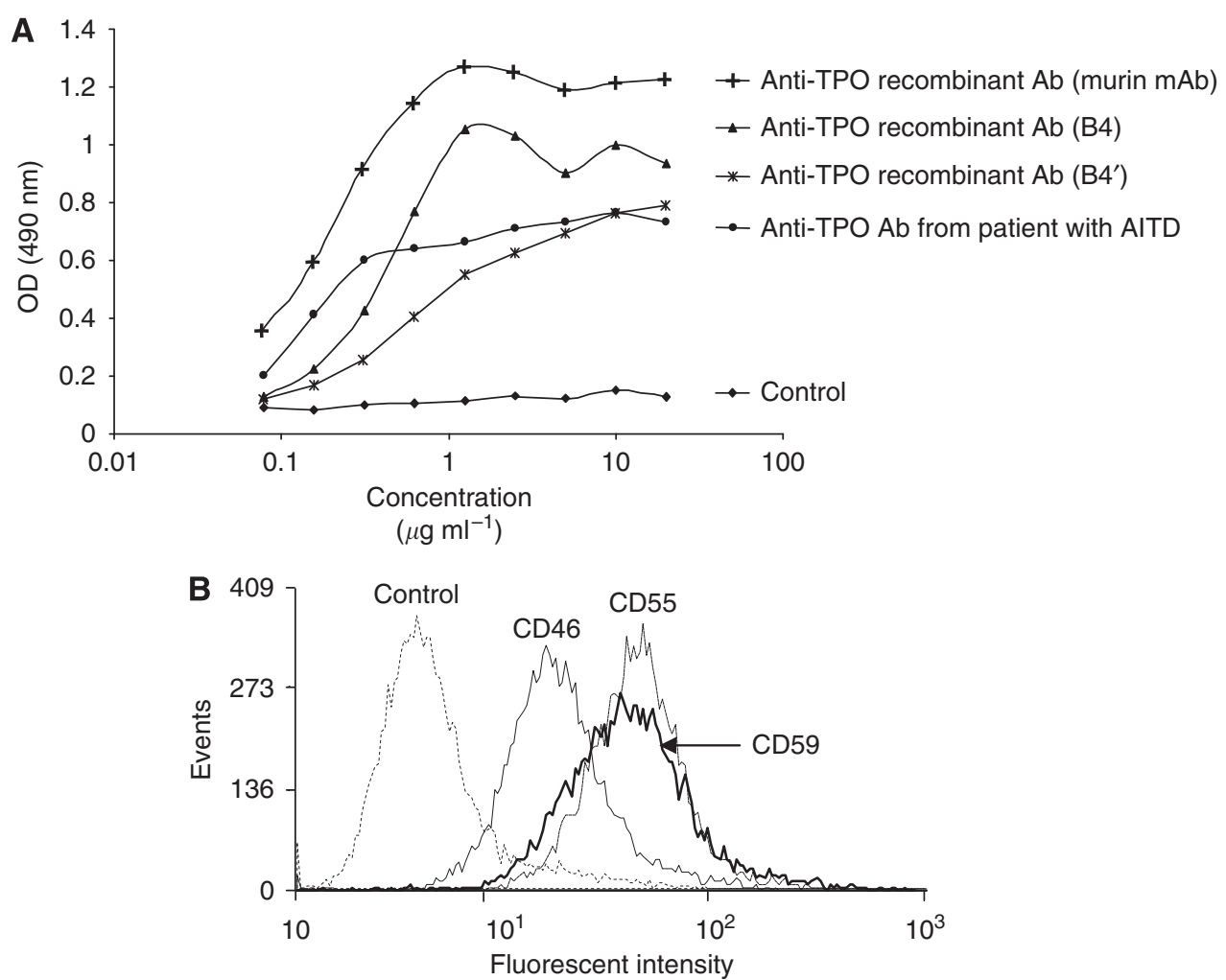

C
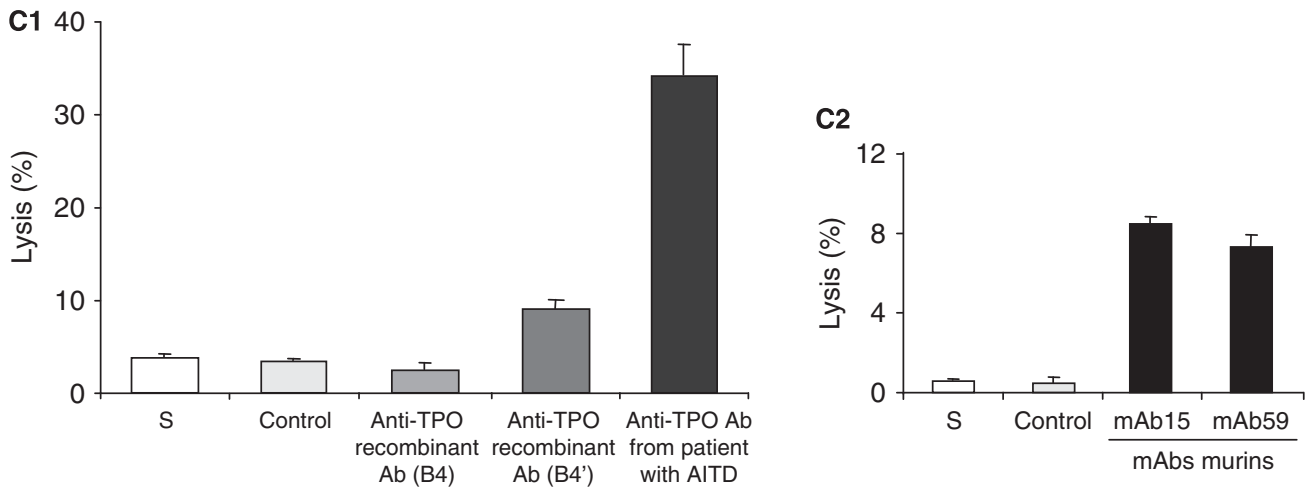

Figure 4 Complement-dependent cytotoxicity mediated by human recombinants (B4 and B4') and patients' sera anti-TPO aAbs. (A) The Clq component of Complement was able to bind to TPO/anti-TPO aAbs complexes but not to an irrelevant lgG. Binding was determined by ELISA. Results are mean of duplicates. (B) Expression of complement regulatory proteins CD46, CD55 and CD59 was investigated on NPA cells, by flow cytometry and the data presented in histograms were overlaid. $(\mathbf{C})$ Complement-dependant cytotoxicity was determined by the ${ }^{51} \mathrm{Cr}$ release assay. $\mathrm{Y}$ axis presents the percentage of NPA cells lysis. NPA cells were lysed by the complement in presence of human (CI) or murin anti-TPO aAbs (C2). Bars, s.d. Results are means of duplicates.

Rebuffat et al, 2006), could make it possible to improve complement activation.

Finally, the use of a mix of anti-TPO aAbs resulting in the simultaneous presence of multiple non-competing TPO epitopes should also improve detection of TPO on cancer cell surface, an essential feature for thyroid cancer treatment. It is now well established that the density of target antigen expressed at the cell surface is essential to obtain a pronounced cytotoxic activity. If compared with the HER-2 antigen in breast cancer, TPO is less expressed in NPA cells, explaining the low levels of complement-, cell-mediated cytotoxicity and anti-proliferative effects we observed. However, studies concerning TPO expression in thyroid cancer yielded discrepant data; some studies reported an inverse correlation between TPO and proliferative cell membrane antigen (Garcia et al, 1998), whereas others pointed to a normal TPO expression in the majority of thyroid carcinomas (more than 65\%) (Czarnocka et al, 2001). Using flow cell sorting technique, we analysed TPO expression on papillary (NPA), follicular (ML1 and WRO) and anaplastic (SW1736 and C643) human thyroid cancer cell lines, and showed that TPO is present on all the cell lines tested even though it was found less expressed in anaplastic and follicular thyroid cancer when compared to papillary carcinoma. These results agree with the study of Czarnocka et al (2001) showing that TPO is still expressed on thyroid cancer cells but not with the study of Garcia et al (1998). These conflicting data could result from differences in the methods and anti-TPO Abs used to detect TPO. Indeed, Garcia et al (1998) investigated TPO expression in a series of thyroid tumours by immunostaining using the anti-TPO mAb47 (Ruf et al, 1989). We have previously shown that lysine 713 has a critical function for TPO epitope recognition by mAb47 


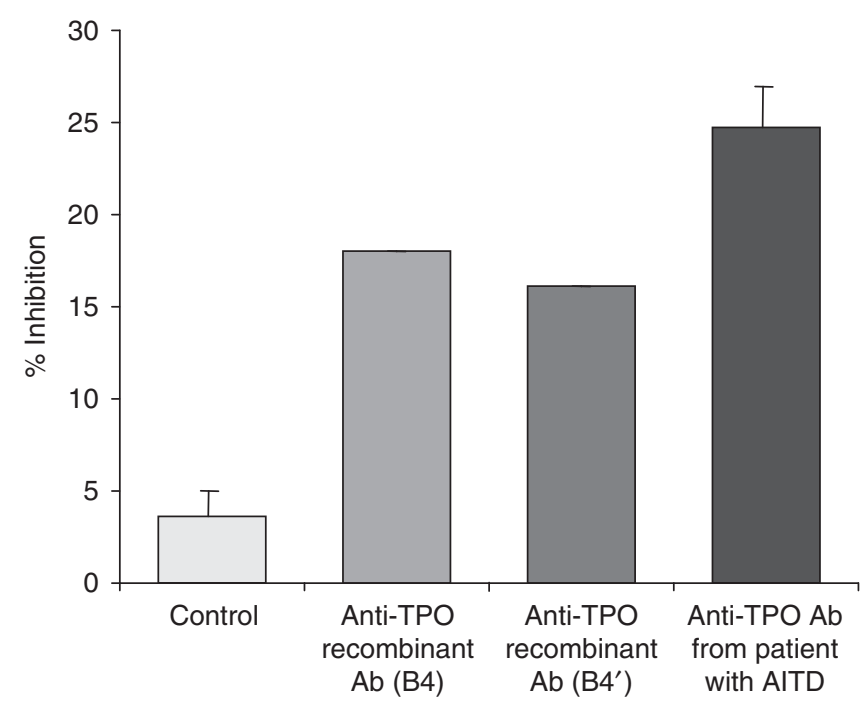

Figure 5 Anti-proliferative effects of anti-TPO aAbs on NPA cells Analysis of growth inhibition of NPA cells cultured for 5 days with recombinants (B4 or B4 $^{\prime}$ ) or patients' sera anti-TPO aAbs as inhibitors Growth was assessed by incorporation of BrdU. Results are representative of three independent experiments.

(Bresson et al, 2004), which is probably strongly impaired by cross-linking of the amino acid on formaldehyde slide fixation. Czarnocka et al (2001) used a TPO capture method that has the advantage to preserve integrity of the antigen structure and thereby allows immunological detection.

\section{REFERENCES}

Alvarez-Rueda N, Leprieur S, Clemenceau B, Supiot S, Sebille-Rivain V, Faivre-Chauvet A, Davodeau F, Paris F, Barbet J, Aubry J, Birklé S (2007) Binding activities and antitumor properties of a new mouse/human chimeric antibody specific for GD2 ganglioside antigen. Clin Cancer Res 13: $5613 \mathrm{~s}-5620 \mathrm{~s}$

Bjorge L, Hakulinen J, Wahlstrom T, Matre R, Meri S (1997) Complementregulatory proteins in ovarian malignancies. Int J Cancer 70: 14-25

Bogner U, Gruters A, Sigle B, Helge H, Schleusener H (1989) Cytotoxic antibodies in congenital hypothyroidism. J Clin Endocrinol Metab 68: $671-675$

Brasoveanu LI, Altomonte M, Fonsatti E, Colizzi F, Coral S, Nicotra MR, Cattarossi I, Cattelan A, Natali PG, Maio M (1996) Levels of cell membrane CD59 regulate the extent of complement-mediated lysis of human melanoma cells. Lab Invest 74: 33-42

Bresson D, Rebuffat SA, Nguyen B, Banga JP, Gardas A, Peraldi-Roux S (2005) New insights into the conformational dominant epitopes on thyroid peroxidase recognized by human autoantibodies. Endocrinology 146: $2834-2844$

Bresson D, Chardes T, Chapal N, Bes C, Cerutti M, Devauchelle G, Bouanani M, Mani JC, Peraldi-Roux S (2001) Pertinence of kappa and lambda recombinant antibodies directed against thyroid peroxidase in thyroid autoimmune disease. Hum Antibodies 10: 109-118

Bresson D, Cerutti M, Devauchelle G, Pugniere M, Roquet F, Bes C, Bossard C, Chardes T, Peraldi-Roux S (2003) Localization of the discontinuous immunodominant region recognized by human anti-thyroperoxidase autoantibodies in autoimmune thyroid diseases. J Biol Chem 278: 9560 - 9569

Bresson D, Pugniere M, Roquet F, Rebuffat SA, N-Guyen B, Cerutti M, Guo J, McLachlan SM, Rapoport B, Estienne V, Ruf J, Chardès T, PéraldiRoux S (2004) Directed mutagenesis in region 713-720 of human thyroperoxidase assigns 713KFPED717 residues as being involved in the $\mathrm{B}$ domain of the discontinuous immunodominant region recognized by human autoantibodies. I Biol Chem 279: 39058-39067

Chapal N, Chardes T, Bresson D, Pugniere M, Mani JC, Pau B, Bouanani M, Peraldi-Roux S (2001) Thyroid peroxidase autoantibodies obtained from
Currently, numerous efforts are being made to develop immunological tools for immunotherapy. The presence of TPO in various thyroid carcinoma and metastases, but not in the other tissues, makes it tempting to target thyroid cancer cells with specific anti-TPO Abs.

Our in vitro data show that anti-TPO aAbs do exhibit some capacities to destroy NPA thyroid tumour cells by ADCC or CDC but in the present state, cannot be considered as suitable for thyroid cancer immunotherapy. Progress has to be made in improving anti-tumour capacities of these anti-TPO recombinant aAbs. This is the matter of our present investigations, with the engineering of CD16/anti-TPO bi-specific aAbs able to physically cross-link immune and tumour cells and thereby to improve cytotoxic activity.

\section{ACKNOWLEDGEMENTS}

This work was supported by the Ligue contre le Cancer, the Association pour la Recherche sur le Cancer (ARC), and the GDR 2352, CNRS 'Immunociblage des tumeurs'. During this study, Sandra A Rebuffat was a recipient from the Ligue Nationale Contre le Cancer and the Association pour la Recherche sur le Cancer. We thank Dr Stephane Birkle (Nantes, France) for providing us the plasmid vectors, his assistance and councils for the antibodies production in the eukaryote system. We also thank Dr André Pélégrin (Montpellier, INSERM-U896, France) and his team for their welcome, their assistance and their advices. We thank Mlle Myriam Chentouf and Mr Samuel Troadec (CNRS-UMR5236, Montpellier, France) for their assistance and their support during flow cytometry experiments. random single chain FV libraries contain the same heavy/light chain combinations as occur in vivo. Endocrinology 142: 4740-4750

Chapal N, Peraldi-Roux S, Bresson D, Pugniere M, Mani JC, Granier C, Baldet L, Guerrier B, Pau B, Bouanani M (2000) Human anti-thyroid peroxidase single-chain fragment variable of Ig isolated from a combinatorial library assembled in-cell: insights into the in vivo situation. J Immunol 164: 4162-4169

Chiovato L, Bassi P, Santini F, Mammoli C, Lapi P, Carayon P, Pinchera A (1993) Antibodies producing complement-mediated thyroid cytotoxicity in patients with atrophic or goitrous autoimmune thyroiditis. J Clin Endocrinol Metab 77: 1700 - 1705

Czarnocka B, Ruf J, Ferrand M, Carayon P, Lissitzky S (1985) Purification of the human thyroid peroxidase and its identification as the microsomal antigen involved in autoimmune thyroid diseases. FEBS Lett 190: $147-152$

Czarnocka B, Pastuszko D, Janota-Bzowski M, Weetman AP, Watson PF, Kemp EH, McIntosh RS, Asghar MS, Jarzab B, Gubala E, Wloch J, Lange $D$ (2001) Is there loss or qualitative changes in the expression of thyroid peroxidase protein in thyroid epithelial cancer? Br J Cancer 85: 875-880 Estour B, Van Herle AJ, Juillard GJ, Totanes TL, Sparkes RS, Giuliano AE, Klandorf H (1989) Characterization of a human follicular thyroid carcinoma cell line (UCLA RO $82 \mathrm{~W}-1$ ). Virchows Arch B Cell Pathol Incl Mol Pathol 57: 167-174

Fagin JA, Matsuo K, Karmakar A, Chen DL, Tang SH, Koeffler HP (1993) High prevalence of mutations of the p53 gene in poorly differentiated human thyroid carcinomas. J Clin Invest 91: 179-184

Garcia S, Vassko V, Henry JF, De Micco C (1998) Comparison of thyroid peroxidase expression with cellular proliferation in thyroid follicular tumors. Thyroid 8: 745-749

Gorter A, Blok VT, Haasnoot WH, Ensink NG, Daha MR, Fleuren GJ (1996) Expression of CD46, CD55, and CD59 on renal tumor cell lines and their role in preventing complement-mediated tumor cell lysis. Lab Invest 74: $1039-1049$

Guo J, Jaume JC, Rapoport B, McLachlan SM (1997) Recombinant thyroid peroxidase-specific Fab converted to immunoglobulin G (IgG) 
molecules: evidence for thyroid cell damage by IgG1, but not IgG4, autoantibodies. J Clin Endocrinol Metab 82: 925-931

Jefferis R, Lund J, Pound JD (1998) IgG-Fc-mediated effector functions: molecular definition of interaction sites for effector ligands and the role of glycosylation. Immunol Rev 163: 59-76

Lifely MR, Hale C, Boyce S, Keen MJ, Phillips J (1995) Glycosylation and biological activity of CAMPATH-1H expressed in different cell lines and grown under different culture conditions. Glycobiology 5: 813-822

Mark J, Ekedahl C, Dahlenfors R, Westermark B (1987) Cytogenetical observations in five human anaplastic thyroid carcinomas. Hereditas 107: $163-174$

McLachlan SM, Rapoport B (1992) The molecular biology of thyroid peroxidase: cloning, expression and role as autoantigen in autoimmune thyroid disease. Endocr Rev 13: $192-206$

McLachlan SM, Rapoport B (2000) Autoimmune response to the thyroid in humans: thyroid peroxidase - the common autoantigenic denominator. Int Rev Immunol 19: 587-618

Metcalfe RA, Oh YS, Stroud C, Arnold K, Weetman AP (1997) Analysis of antibody-dependent cell-mediated cytotoxicity in autoimmune thyroid disease. Autoimmunity 25: 65-72

Ortaldo JR, Woodhouse C, Morgan AC, Herberman RB, Cheresh DA, Reisfeld R (1987) Analysis of effector cells in human antibody-dependent cellular cytotoxicity with murine monoclonal antibodies. J Immunol 138: $3566-3572$

Parkes AB, Othman S, Hall R, John R, Richards CJ, Lazarus JH (1994) The role of complement in the pathogenesis of postpartum thyroiditis. J Clin Endocrinol Metab 79: 395-400

Peltz GA, Trounstine ML, Moore KW (1988) Cloned and expressed human Fc receptor for IgG mediates anti-CD3-dependent lymphoproliferation. J Immunol 141: $1891-1896$

Rebuffat SA, Bresson D, Nguyen B, Peraldi-Roux S (2006) The key residues in the immunodominant region 353-363 of human thyroid peroxidase were identified. Int Immunol 18: 1091 - 1099
Rebuffat SA, Nguyen B, Robert B, Castex F, Peraldi-Roux S (2008) Antithyroperoxidase antibody-dependent cytotoxicity in autoimmune thyroid disease. J Clin Endocrinol Metab 93: 929-934

Rodien P, Madec AM, Ruf J, Rajas F, Bornet H, Carayon P, Orgiazzi J (1996) Antibody-dependent cell-mediated cytotoxicity in autoimmune thyroid disease: relationship to antithyroperoxidase antibodies. J Clin Endocrinol Metab 81: 2595-2600

Ruf J, Toubert ME, Czarnocka B, Durand-Gorde JM, Ferrand M, Carayon P (1989) Relationship between immunological structure and biochemical properties of human thyroid peroxidase. Endocrinology 125: $1211-1218$

Schonberger J, Bauer J, Spruss T, Weber G, Chahoud I, Eilles C, Grimm D (2000) Establishment and characterization of the follicular thyroid carcinoma cell line ML-1. J Mol Med 78: 102-110

Steplewski Z (1993) Advances and outlooks for immunotherapy of cancer. Hybridoma 12: $493-500$

Tao MH, Morrison SL (1989) Studies of aglycosylated chimeric mouse-human IgG. Role of carbohydrate in the structure and effector functions mediated by the human IgG constant region. J Immunol 143: $2595-2601$

van Vugt MJ, Kleijmeer MJ, Keler T, Zeelenberg I, van Dijk MA, Leusen JH, Geuze HJ, van de Winkel JG (1999) The FcgammaRIa (CD64) ligand binding chain triggers major histocompatibility complex class II antigen presentation independently of its associated FcR gamma-chain. Blood 94: $808-817$

Vivier E, Rochet N, Ackerly M, Petrini J, Levine H, Daley J, Anderson P (1992) Signaling function of reconstituted CD16:zeta:gamma receptor complex isoforms. Int Immunol 4: 1313-1323

Wadeleux P, Winand-Devigne J, Ruf J, Carayon P, Winand R (1989) Cytotoxic assay of circulating thyroid peroxidase antibodies. Autoimmunity 4: 247-254

Wright A, Morrison SL (1997) Effect of glycosylation on antibody function: implications for genetic engineering. Trends Biotechnol 15: 26-32 